\title{
Waning of aggressive motivation in Betta splendens
}

RONALD BAENNINGER

THE JOHNS HOPKINS UNIVERSITY

Siamese fighting fish showed a waning tendency to view both their own reflections and a similar fish during trials lasting $32 \mathrm{hr}$. Although both stimuli elicited aggressive displays, all Ss spent more time viewing their rèflections than viewing the live stimulus fish.

Recent experiments have shown that the opportunity to perform an aggressive display may serve as reinforcement in the acquisition of operant responses (Thompson, 1963; Thompson, 1964). The possibility exists that the demonstrated "extinction" of these responses is due to a waning tendency to approach stimuli which elicit aggressive displays, or even to avoidance of such stimuli. Clayton has shown that repeated elicitation of the aggressive display itself results in its habituation. 1

In the present experiment the position preferences of Siamese fighting fish (Betta splendens) were observed individually as a function of time in a 3-alternative choice situation. Position of the $\mathrm{S}$ was assumed to represent a choice among three portions of a rectangular tank, at one end of which was a mirror. At the opposite end was another betta in a separate tank; no stimuli were visible to the $S$ in the center portion of the experimental tank. Position of the S was studied since such data could give evidence regarding approach or avoidance responses to the stimuli, both of which are capable of eliciting vigorous aggressive displays. Subjects

Ss were five naive male Siamese fighting fish. The stimulus fish was another betta which had been habituated to his reflection in a mirror so that he displayed only briefly at the beginning of each trial. All fish were approximately the same size and color.

\section{Apparaius}

The rectangular experimental tank measured 4-1/2 $\mathrm{x}$ $18 \times 6$ in., and was made of clear plexiglas. The small tank for the stimulus fish was clear glass and measured $3 \times 4 \times 6$ in.

\section{Procedure}

Each S spent 32 consecutive hours in the main tank in two conditions. In the Control condition, neither the mirror nor the stimulus fish was present at the ends of the main tank. A trial began when a $S$ was placed at the midpoint of the main tank. Observations lasting $15 \mathrm{~min}$. were made initially and at $1,2,4,8,16$, and $32 \mathrm{hr}$. thereafter, after which the S was removed and fed. In the Experimental condition, which began $16 \mathrm{hr}$. after the end of the Control condition, the mirror and stimulus fish were present at the tank ends. In all other respects the procedure was identical to the Control condition. The amount of time during which the S's anterior end (as far back as its gill membrane slits) was in each portion of the tank was recorded during 15-min. observation periods.

When not in the main tank fish were housed in individual round jars surrounded by opaque material, and were fed only in these jars. Water temperature remained at $72^{\circ} \mathrm{F}$., and illumination was provided by a 40 watt bulb $2 \mathrm{ft}$. above the center of the main tank. Results

The principal results are shown in Fig. 1 where mean time spent in the center portion of the tank ("center time") during each observation period is plotted against $\log _{2}$ of the time in hours following the beginning of each trial. Each data point represents the mean of five fish. A trend test was performed on these means by computing the correlation coefficient between number of the observation period and mean center time for that observation period. In the Control condition there was no significant correlation, but the upward trend in the Experimental condition was significant $(\mathrm{r}=0.78 ; \mathrm{p}<0.05)$.

In order to see whether the variability of the data observed obscured the upward trend, the Fisher exactprobability test was applied to the center time data in the following way. The grand mean of all Ss and observations was calculated for each condition. The number of scores falling above and below this mean in the first three and in the last three observation periods of the relevant condition were found and entered in a 2 by 2 table. A trend in a condition between the first

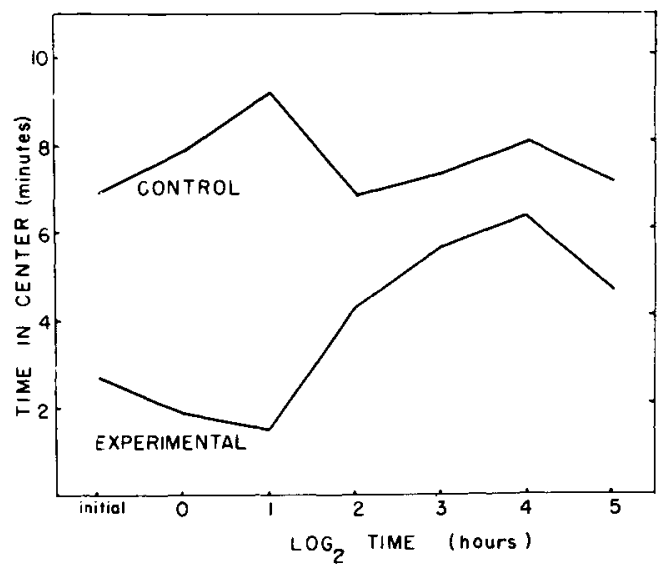

Fig. 1. Mean time spent in center portion of tank during observations of $15 \mathrm{~min}$. duration. In the Experimental condition stimuli were present in the ends of the tank but not visible from the center portion. In the Control condition no stimuli were present. 
three and last three observation periods would thus be indicated by a change in the distribution of scores above and below the mean. The Fisher test indicated a significant trend for the Experimental condition $(p=0.02)$; the trend was not significant in the Control $(p=0.22)$ supporting the above finding of a trend in the Experimental condition only.

The data on amount of time spent in front of both the mirror and the stimulus fish were analyzed, but no significant trends at either end were found in either condition. Thus, the increased preference for the center of the tank, which was found in the last three Experimental observations, did not result from consistent trends in the time spent at either end.

During the Control condition all Ss showed a bias toward the ends of the tank, making the trend toward the center in the Experimental condition more marked. Since the center portion made up two-thirds of the tank volume a mean of $10 \mathrm{~min}$. out of 15 would be expected for center time if all positions were equally likely. Only one S spent this much time in the center during the entire Control condition, and the amount of time spent in each end of the tank remained approximately constant and equal, for each S.

Regardless of which end of the tank they went to initially in the Experimental condition, all fish spent more total time during seven observations in front of the mirror than in front of the fish. The ratio of total "mirror time" to "fish time" was nearly three to one. All Ss exhibited this pronounced preference for their own reflection over the sight of the real betta, although no qualitative differences in response to the two stimuli were noted.

\section{Discussion}

It seems clear that in the Experimental condition fish spent an increasing proportion of their time out of sight of the stimuli which elicited aggressive displays. This changing preference cannot be considered avoidance, since the center time in the Experimental condition was never significantly greater than in the Control condition, but the result does indicate a decreasing tendency to view stimuli which elicit aggressive displays. It appears that the reinforcing properties of such stimuli may exist for a limited time only, and that the extinction reported by Thompson may be due to this decreased tendency to approach mirrors and stimulus fish. Longer trials might show avoidance of these stimuli, but confounding with food deprivation effects or fatigue would be likely. In the later observations two fish were observed to swim rapidly away from the mirror whenever they caught sight of their reflections. Very few displays were noted during the last three observation periods, compared to initial continuous displaying by all subjects. This finding suggests that habituation of the display itself was occurring, and supports the more exact findings of Clayton. It thus appears that the tendency to approach stimuli which elicit the aggressive display, and the display itself, are subject to habituation.

\section{References}

Thompson, T. I. Visual reinforcement in siamese fighting fish. Science, $1963,141,55-57$

Thompson, T. I. Visual reinforcement in fighting cocks. J. exp Anal. Behav., 1964, 7, 45-49.

\section{Note}

1. F. L. Clayton, Personal communication (1965).

\section{Errata}

THOMPSON, R. F., DENNEY, DUANE, \& SMITH, H . E. Cortical control of specific and nonspecific sensory projections to the cerebral cortex. Psychon. Sci., 1966, 4(3), 93-94.-The second author's name should be spelled both on the cover and in the article itself as Denney (not Denny).
FRANK, R., \& KENYON, J. Visual cliff behavior of mice as a function of genetic differences in eye characteristics. Psychon. Sci., 1966, 4(1), 35-36.-The second author's name is Kenyon, not Kenton. Line 7 of the first paragraph after the abstract should read ". . . whether a selective breeding process .. ."not "a type of." In the paragraph following, line 6 should read ". . . effects of type of breeding," not "selective breeding." 